\title{
O ESTADO DE BEM-ESTAR SOCIAL NO BRASIL
}

\section{THE STATE OF SOCIAL WELFARE IN BRAZIL}

\section{CARINA PESCAROLO}

Mestranda em Direito Empresarial e Cidadania pela Faculdade de Direito do Centro Universitário Curitiba (Unicuritiba), carinapescarolo@gmail.com.

\section{SORAIA PAULINO MARCHI}

Mestranda em Direito Empresarial e Cidadania pela Faculdade de Direito do Centro Universitário Curitiba (Unicuritiba), adv.marchi@yahoo.com.br.

\section{RESUMO}

O presente artigo tem por finalidade analisar com base na pesquisa bibliográfica se é aplicável o Estado de bem-estar social no Brasil e se pode ser efetivo. Discorre sobre como se originaram o Estado liberal (burguês) e o Estado social ou de providência (intervencionista), posicionando-os na história, tanto das revoluções quanto das crises que os embasaram, traçando seus conceitos, características, aplicação e crises. Buscar demonstrar o contexto histórico, com base nas Constituições brasileiras, desde a imperial de 1824 até a democrática de 1988, a origem do Estado de bem-estar social no Brasil, até que ponto tem respaldo para ser aplicado, se pode ser efetivo ou não.

PALAVRAS-CHAVE: Estado liberal; Estado do bem-estar social; Estado social; Estado de providência; Brasil. 
Personalidade Acadêmica Homenageada:

Florisbal de Souza Del'Olmo (Professor Convidado - UNICURITIBA)

\section{ABSTRACT}

The purpose of this article is to analyze, based on bibliographical research, whether the State of social welfare in Brazil is applicable and can be effective. It discusses how the liberal (bourgeois) state and the social or providential state (interventionist) originated, placing them in the history of both the revolutions and the crises that underpinned them, tracing their concepts, characteristics, application and crises. Seeking to demonstrate the historical context, based on the Brazilian Constitutions, from the imperial of 1824 to the democratic of 1988 , the origin of the welfare state in Brazil, to what extent has support to be applied, whether it can be effective or not .

KEYWORDS: Liberal state; State of social welfare; Social state; State of providence; Brazil.

\section{INTRODUÇÃO}

O presente texto buscará analisar se no Brasil existe ou existiu o Estado do bem-estar social, também chamado de Estado social e Estado de providência.

Para tanto, com fundamento em pesquisas bibliográficas, discorrerá necessariamente sobre o Estado liberal e sua base na ascensão burguesa ao poder, e o Estado do bem-estar social intervencionista, posicionando historicamente os acontecimentos que lhes deram origem, como as revoluções, francesa que originou o primeiro, e a do proletariado que originou a segunda, bem como as crises econômicas que instigaram as rupturas de um modelo para o outro.

Buscará estabelecer seus conceitos, características e finalidades, bem como a transição de um para o outro.

Procurará demonstrar o contexto histórico, com base nas Constituições brasileiras, da origem do Estado de bem-estar social no Brasil, desde a Constituição Imperial de 1824 e até a Constituição democrática de 1988, vigente nos dias atuais. Tentará entender até que ponto o Estado social tem respaldo para ser aplicado no Brasil e se pode ser efetivo ou não. 
Personalidade Acadêmica Homenageada:

Florisbal de Souza Del'Olmo (Professor Convidado - UNICURITIBA)

\section{ESTADO LIBERAL}

O Estado liberal institucionalizou-se após a Revolução Francesa de 1789, no fim do século XVIII. A Revolução de 1789 foi uma revolta social da burguesia, que detinha o dinheiro, mas não o poder, e colocou fim ao Estado monárquico autoritário, passando de classe dominada e discriminada para dominante e discriminadora.

O lema dos revolucionários era: "Liberdade, Igualdade e Fraternidade", que resumia os reais desejos da burguesia: liberdade individual para a expansão dos seus negócios e a obtenção de lucro; igualdade jurídica com a aristocracia visando à abolição das discriminações; e fraternidade dos camponeses e sans-cullotes ${ }^{1}$ com o intuito de que apoiassem a revolução e lutassem por ela.

Leo Hubermann no livro a História da riqueza do homem (1986, p.151), relata o que de fato ocorria durante a Revolução:

Marat, o porta-voz da classe trabalhadora mais pobre, descreveu o que ocorria durante a Revolução, com as seguintes palavras: "No momento da insurreição o povo abriu caminho através de todos os obstáculos pela força do número; mas, por muito poder que tenha conseguido inicialmente, foi por fim derrotado pelos conspiradores da classe superior, cheios de astúcia, artimanhas e habilidade. Os integrantes educados e sutis da classe superior a princípio se opuseram aos déspotas; mas isso apenas para voltar-se contra o povo, depois de se ter insinuado na confiança e usado seu poder, para se colocarem na posição privilegiada da qual os déspotas haviam sido expulsos.

Ensina ainda Huberman (1986, p.151):

A revolução é feita e realizada por intermédio das camadas mais baixas da sociedade, pelos trabalhadores artesãos, pequenos comerciantes, camponeses, pela plebe, pelos infelizes, a que ricos desavergonhados chamam de canalha e a que os romanos desavergonhadamente chamavam de proletariado. Mas o que as classes superiores ocultam constantemente é o fato de que a Revolução acabou beneficiando somente os donos de terras, os advogados e os chicaneiros. (History of the Working Class, Lesson I, Course 2. International Publishers, N.)

\footnotetext{
${ }^{1}$ Sans-culottes foi um dos grupos mais atuantes da Revolução Francesa, e eram assim chamados pelo fato de usarem calças compridas e largas, diferente dos ricos que usavam calças curtas e apertadas até a altura do joelho, chamadas de cullotes.
} 


\section{Personalidade Acadêmica Homenageada:}

Florisbal de Souza Del'Olmo (Professor Convidado - UNICURITIBA)

Do relato evidencia-se o interesse individualista da burguesia pelo poder, iludindo e subjugando a classe proletária para que lutassem contra $\circ$ Estado monárquico. A classe burguesa detinha o poder econômico, e com a Revolução, também passou a deter o poder político, antes dominado pela realeza e pela nobreza.

Paulo Bonavides em sua obra Do Estado liberal ao Estado social ensina que o liberalismo tem como princípios a liberdade e a separação dos poderes e "Essa liberdade Ihe era indispensável para manter o domínio do poder político". Destaca ainda o autor (2007, p. 44):

\footnotetext{
Disso não advinha para a burguesia dano algum, senão muita vantagem demagógica, dada a completa ausência de condições materiais que permitissem às massas transpor as restrições do sufrágio e, assim concorrer ostensivamente, por via democrática, à formação da vontade estatal.
}

No tocante à teoria da separação dos poderes de Locke, adotada pelo Estado liberal através da influência de Montesquieu, José de Albuquerque Rocha (1995, p. 128) observa que o objetivo de Montesquieu ao introduzir os poderes Executivo, Legislativo e Judiciário, era preservar os privilégios da sua própria classe, a nobreza, ameaçada tanto pelo rei, que desejava recuperar sua influência nacional, quanto pela burguesia, que detentora do poder econômico, visava dominar também o poder político. Sua teoria dividia o poder entre a burguesia, nobreza e realeza, afastando, deste modo, a possibilidade da burguesia em crescimento ser a sua única detentora.

O Estado liberal impôs limitações ao poder soberano, por meio da concepção de lei geral e abstrata, portadora de uma igualdade estritamente formal e do abstencionismo econômico, pois objetivava a criação de um mercado autorregulado imune a interferências estatais de qualquer gênero, visando atribuir segurança jurídica às trocas mercantis, com mão de obra barata, objetivando cada vez mais lucro.

É o princípio da não intervenção do Estado na economia, considerado uma estratégia da burguesia para evitar a ingerência dos antigos monarcas e senhores 


\section{Personalidade Acadêmica Homenageada:}

Florisbal de Souza Del'Olmo (Professor Convidado - UNICURITIBA)

feudais na economia da época, garantindo a liberdade individual para a expansão dos seus negócios e a obtenção do lucro.

Mas o Estado liberal entrou em crise, pois não pode resolver o problema essencial de ordem econômica das camadas proletárias da sociedade. A principal transformação porque passou, foi o reconhecimento geral da liberdade política, mediante o sufrágio universal, conquistado através da revolução oriunda do conflito entre o trabalho e o capital.

Com o sufrágio universal, o proletariado ingressava de fato na democracia política, e o liberalismo dava mais um passo para o desaparecimento, pois obrigatoriamente teve que abrir mão da liberdade política como liberdade de classe, que antes dava o controle do Estado à burguesia. Perdeu o poder de fazer o governo e a lei, de manter a ordem política distante da esfera econômica.

Segundo Bonavides (2007, p.189), essa concessão (sufrágio universal), na verdade salvou e preservou ideologicamente o que havia de melhor na antiga tradição liberal: "a ideia de liberdade moderna, liberdade como valoração da personalidade, agora já no âmbito da democracia plesbicitaria, vinculada ao Estado social. " Destaca ainda que:

Com a reconciliação entre capital e trabalho, por via democrática, todos lucram. Lucra o trabalhador, que vê suas reinvindicações mais imediatas e prementes atendidas satisfatoriamente, numa fórmula de contenção de egoísmo e de avanço para formas moderadas do socialismo fundado sobre o consentimento. E lucram também os capitalistas, cuja sobrevivência fica afiançada no ato de sua humanização, embora despojados daqueles privilégios de exploração impune, que constituíam a índole sombria do capitalismo, nos primeiros tempos em que se implantou (BONAVIDES, 2007, P.189)

Contextualiza ainda o autor (2007, p. 190), afirmando que a vitória sufragista da massa era criticada erroneamente, pela burguesia de pouca visão, pois entendiam que esta também Ihe tomava os privilégios, deslocando a ideia política da polaridade individual para a polaridade social. Não viam que não havia perigo de ser extinto o sistema capitalista, e que o sufrágio universal eliminava o recurso à violência revolucionária pregada no Manifesto comunista de Marx. 


\section{Personalidade Acadêmica Homenageada:}

Florisbal de Souza Del'Olmo (Professor Convidado - UNICURITIBA)

O Estado liberal previa maior liberdade para 0 mercado, sem a regulamentação do Estado; vigorou no século XIX, mas entrou em profunda crise no início do século XX, com a Primeira Guerra Mundial, que entre outras coisas, foi resultado da disputa por mercados travada pelos países europeus, tendo encerrado um período de desenvolvimento. A crise de 1929, decorrente da superprodução americana que o mercado foi incapaz de absorver, teve como solução justamente a retomada da regulamentação econômica pelo Estado.

Defensores do liberalismo acreditavam que a intervenção do Estado na economia e o investimento em políticas sociais eram, na verdade, gastos prejudiciais à economia, no entanto, essas duas medidas impulsionaram seu crescimento, dando origem ao Estado social.

\section{ESTADO SOCIAL OU ESTADO DE PROVIDÊNCIA OU ESTADO DO BEM- ESTAR SOCIAL}

A igualdade tão somente formal aplicada à sociedade e a abstenção do Estado liberal em face das questões sociais, apenas serviram para expandir o capitalismo e agravar a situação da classe trabalhadora, que vivia sob condições miseráveis.

O descompromisso do Estado liberal com as questões sociais, agravado pela eclosão da Revolução Industrial, que submetia o trabalhador a condições desumanas e degradantes, a ponto de algumas empresas exigirem o trabalho diário por mais de doze horas ininterruptas, culminou com a Revolução Russa de 1917, conduzindo os trabalhadores a se organizarem com o objetivo de resistir à exploração.

Esse movimento possibilitou a ruptura do Estado Liberal, devido a grande adesão de operários do ocidente europeu. A burguesia, com medo de se espalhar os ideais pregados pela Revolução Russa, buscou mecanismos que afastassem os trabalhadores da opção revolucionária, surgindo, então, o Estado social, que tinha 
Personalidade Acadêmica Homenageada:

Florisbal de Souza Del'Olmo (Professor Convidado - UNICURITIBA)

como características: i) intervenção do Estado na economia, ii) aplicação do princípio da igualdade material e iii) realização da justiça social.

Outro ponto de ruptura do Estado liberal ocorreu diante da total liberdade econômica que se transformou em um capitalismo monopolista, culminando, no fim do século XIX, com o surgimento nos Estados Unidos da legislação antitruste, que proibia os acordos de domínio de mercado, numa tentativa de tentar manter o modelo natural de mercado autorregulável, pregado pelo liberalismo clássico.

Essa tentativa de manter o Estado liberal, acabou por se tornar um dos fatores de superação desse modelo, que ao admitir a necessidade de intervenção/regulação da economia pelo Estado, deu margem a um momento de ruptura, à passagem para um modelo de Estado que intervém na ordem social e econômica.

Mais um ponto de ruptura se deu com a quebra da bolsa de Nova York em 1929 e a crise da década de 30, que levou o Presidente norte-americano, Franklin Roosevelt, a adotar políticas públicas intervencionistas, que se tornaram conhecidas como New Deal, que tinha como objetivo por fim ao colapso econômico e resgatar a sociedade do desemprego.

Bresser-Pereira, ao escrever o artigo Reforma gerencial e legitimação do estado social para a Revista de Administração Pública da Fundação Getúlio Vargas, traça um resumo conciso acerca das origens do Estado social:

O estado social nasce no após-guerra, a partir do otimismo gerado pela vitória contra o nazismo, o relativo êxito da União Soviética no quadro de um regime que naquela época era ainda considerado como socialista, e do aumento do poder dos sindicatos de trabalhadores e dos partidos sociaisdemocratas. Dadas essas demandas, a solução encontrada pelas democracias liberais foi montar os grandes serviços sociais universais de educação, saúde e previdência social, que são substancialmente mais eficientes em aumentar o padrão de vida da população do que o simples aumento dos salários reais. Assistimos, então, à transição de um Estado democrático liberal, que correspondia a uma democracia de elites, para um Estado democrático social. E também para um Estado desenvolvimentista, porque o Estado volta a ter um papel importante na promoção do desenvolvimento econômico. 
Personalidade Acadêmica Homenageada:

Florisbal de Souza Del'Olmo (Professor Convidado - UNICURITIBA)

Boaventura Sousa Santos, ao escrever um artigo para o Diário de Notícias ${ }^{2}$ sob o tema Estado social, Estado providência e de bem-estar, ensina:

\begin{abstract}
O Estado social é o resultado de um compromisso histórico entre as classes trabalhadoras e os detentores do capital. Este compromisso foi a resposta a uma dolorosa história recente de guerras destrutivas, lutas sociais violentas e crises econômicas graves. Nos termos desse compromisso ou pacto, os capitalistas renunciam a parte da sua autonomia enquanto proprietários dos fatores de produção (aceitam negociar com os trabalhadores temas que antes lhes pertenciam em exclusividade) e a parte dos seus lucros no curto prazo (aceitam ser mais fortemente tributados), enquanto os trabalhadores renunciam às suas reivindicações mais radicais de subversão da economia capitalista (o socialismo e, para o atingir, a agitação social sem condições face à injustiça da exploração do homem pelo homem). Esta dupla renúncia é gerida pelo Estado, o que confere a este alguma autonomia em relação aos interesses contraditórios em presença.
\end{abstract}

Estado Social, ou de providência ou do bem-estar social, surgiu após o advento da II Guerra Mundial, representando efetivamente uma transformação estrutural por que passou o antigo Estado liberal. Contudo, é diverso do Estado proletário, que o socialismo marxista intenta implantar, pois conserva sua adesão à ordem capitalista, princípio cardeal a que não renunciou.

Bonavides (2007, p. 32), ensina:

Já o Estado social propriamente dito - não o do figurino totalitário, quer de extrema esquerda, quer de extrema direita - deriva do consenso, das mutações pacíficas do elemento constitucional da Sociedade, da força desenvolvida pela reflexão criativa e, enfim, dos efeitos lentos, porém seguros, provenientes da gradual acomodação dos interesses políticos e sociais, volvidos, de último, ao seu leito normal.

José Afonso da Silva ao escrever sobre o Estado Democrático de Direito na Revista de Direito Administrativo (1988, p. 20), ensina que o Estado social caracteriza-se por tentar compatibilizar dois elementos num mesmo sistema: "o capitalismo, como forma de produção, e a consecução do bem-estar social geral, servindo de base ao neocapitalismo típico do Welfare State ${ }^{3 \prime}$.

\footnotetext{
${ }^{2}$ Jornal português on-line, de edição diária.

${ }^{3}$ Estado de bem-estar que teve origem no pensamento keynesiano (Economista John Maynard Keynes).
} 
Personalidade Acadêmica Homenageada:

Florisbal de Souza Del'Olmo (Professor Convidado - UNICURITIBA)

Paulo Bonavides em sua obra Do Estado liberal ao Estado social (2007, p. 200), afirma:

O Estado social, por sua própria natureza, é um Estado intervencionista, que requer sempre a presença militante do poder político nas esferas sociais, onde cresceu a dependência do indivíduo, pela impossibilidade em que este se acha, perante fatores alheios à sua vontade, de prover certas necessidades existenciais mínimas.

A partir da década de 1930, expandiu-se o modelo chamado de Estado de bem-estar social, no qual o Estado é organizador da política e da economia, promovendo e defendendo o social. Passa a atuar ao lado de sindicatos e empresas privadas, com o intuito de garantir serviços públicos e proteção à população.

A principal característica reside no Estado que se incorpora aos direitos sociais, mas não apaga e nem subverte liberdades, principalmente as liberdades políticas, bem como os direitos e garantias individuais. O Estado do bem-estar social afasta o liberalismo econômico, mas continua fiel ao liberalismo político, e, exige para o Estado um papel insubstituível na economia, mas não exclui a iniciativa privada e o mercado.

O Estado social foi o modelo predominante nos países ocidentais na segunda metade do século XX. Defendia o desenvolvimento do mercado, porém acompanhado de políticas públicas e da interferência do Estado na economia para corrigir os erros e proteger a população. Atualmente, diz-se que o modelo está em crise, desde as décadas de 1970 e 1980, sendo constantemente atacado por ideologias chamadas neoliberais, que se identificam com as políticas do Estado liberal.

\section{ESTADO DO BEM-ESTAR SOCIAL NO BRASIL}

Paulo Bonavides em Reflexões sobre nação, Estado social e soberania, (2008, p. 200), ensina que o "pensamento precursor do Estado social no Brasil, a grande surpresa que nos depara é verificar que ele nasceu no Império e não na 


\section{Personalidade Acadêmica Homenageada:}

Florisbal de Souza Del'Olmo (Professor Convidado - UNICURITIBA)

República." O projeto constituinte de 1823 , no Título XIII dispunha: Da instrução pública, estabelecimentos de caridade, casas de correção e trabalho.

O art. 250 rezava: "Haverá no Império escolas primárias em cada termo, ginásios em cada comarca e universidades nos mais apropriados locais". E o art. 255, encerrava o Título XIII dispondo: "Erigir-se-ão casas de trabalho para os que não acham emprego....".

Vislumbra-se nesses artigos a tendência protetora da população/súditos pelo Imperador, demonstrando indícios do Estado de bem-estar social.

A Constituição outorgada em 1824 pelo Imperador D. Pedro I, também trazia "o germe das regras sociais no art. 179, afiançando que a Constituição também garante os socorros públicos, que a instrução primária é gratuita, que em colégios e universidades serão ensinados os elementos das ciências, belas-letras e artes. " (BONAVIDES, 2008, p. 200)

Evidentes os indícios do Estado do bem-estar social nesses dois textos constituintes, que dispunham sobre proteção social em relação à educação e ao emprego. Diferente da constituinte da República de Rui Barbosa em 1891, que não previa qualquer tipo de direitos sociais.

A partir da década de 1920, com manifestações políticas e da sociedade contra o imobilismo do Estado liberal em relação a questões sociais, com os levantes militares dos dois 5 de julho ${ }^{4}$, com o governo repressivo do presidente Artur Bernardes, nasce um forte sentimento de nacionalidade e proteção à riqueza nacional, que culmina com a revolução de 1930 que pôs fim a república velha, seguida da Constituição de 1934, que inaugurou "as primeiras formas concretas e rudimentares de Estado social". (BONAVIDES. 2008, p. 201)

A intervenção estatal na economia nacional teve início na Era Vargas (19301945) e chegou ao auge durante o período da ditadura militar (1964-1985). O absurdo, é que os mais beneficiados com os gastos públicos em infra-estrutura (nas áreas de telecomunicações, energia elétrica, auto-estradas, etc.) e construção de grandes empresas públicas foram, justamente, os empresários brasileiros e

\footnotetext{
${ }^{4}$ Levante do Forte de Copacabana, em 5 de julho de 1922, e Revolta Vermelha em 5 de julho de 1935.
} 


\section{Personalidade Acadêmica Homenageada:}

Florisbal de Souza Del'Olmo (Professor Convidado - UNICURITIBA)

estrangeiros, em detrimento da manutenção da acentuada desigualdade social, dos elevados índices de pobreza e do insucesso no Índice de Desenvolvimento Humano.

Bonavides e Andrade na obra História constitucional do Brasil (2006, p. 325), destacam que:

Pela primeira vez na história constitucional brasileira, considerações sobre a ordem econômica e social estiveram presentes. Uma legislação trabalhista garantia a autonomia sindical, a jornada de oito horas, a previdência social e os dissídios coletivos.

Tratava-se da primeira Constituição programática do país.

Em 1937, Getúlio Vargas outorga nova Constituição e, junto com ela, emerge o Estado Novo, fomentador da industrialização e do nacionalismo econômico. Embora o Estado social tenha se mantido em alguma medida, houve atropelo a diversos valores do Estado democrático de direito.

A Constituição de 1946 simbolizava a redemocratização, com o Presidente Eurico Dutra, retomando os princípios liberais e democráticos, e mantendo algumas conquistas do Estado social iniciadas na Era Vargas. Reservou-se um título próprio para a "Ordem Econômica e Social" no qual eram disciplinados os direitos trabalhistas, a nacionalização das empresas de seguro e dos bancos de depósito, entre outras medidas. Em outro título, reconheceu a proteção estatal à família, à educação e à cultura.

Com o golpe militar de 1964, instaura-se a Constituição de 1967, que manteve o programa de intervenção do Estado na ordem econômica, a proteção dos direitos trabalhistas, previsão de reforma agrária, entre outras diretrizes. Contudo, não eram cumpridas ou efetivadas.

Segundo o cientista social Renato Cancian, o Brasil teve dois grandes surtos de expansão dos sistemas de proteção social no Brasil, que ocorreram durante regimes autoritários e sob o governo de coalizões conservadoras. Contudo, nunca chegou a estruturar um Estado de bem-estar semelhante aos dos países nórdicos de primeiro mundo. 
Personalidade Acadêmica Homenageada:

Florisbal de Souza Del'Olmo (Professor Convidado - UNICURITIBA)

No período de transição do governo autoritário para a democracia, os partidos políticos de esquerda e os movimentos populares acreditavam que tinha chegado o momento do Estado brasileiro saldar a imensa dívida social diante das profundas desigualdades sociais e pobreza extrema reinantes no país. Entretanto, tais anseios não se desenvolveram, nem sob a égide da Constituição Federal de 1988, que prevê inúmeros direitos sociais e da proteção da ordem social.

Os três poderes foram reorganizados. O Executivo, apesar do abuso no uso de medidas provisórias e de certas omissões, tem atuado na promoção de políticas públicas. O Legislativo, a despeito das omissões, tem aprovado Emendas à Constituição, como a que inclui o direito à moradia no art. 60, e leis para efetivar direitos sociais, bem como tem procurado fiscalizar os demais poderes. Desconsiderando sua morosidade, o Judiciário tem cumprido o importante papel de guardião da Constituição e, de proteger os direitos sociais e fiscalizar os demais poderes. As promessas da Constituição de 1988 estão longe de terem sido todas concretizadas, mas se trata da Constituição mais efetiva da nossa história, mesmo sujeita aos arbítrios de quem deveria aplicá-la.

Alguns exemplos de questões sociais previstas na Carta Magna brasileira: o art. 201 dispõe sobre a Previdência Social, regulamentado pelo arts. 10 a 16 da Lei $8.213 / 91$, onde somente os contribuintes do sistema têm acesso a benefícios previdenciários; a assistência social é prestada a quem dela necessitar independentemente de contribuição, conforme art. 203, V., Porém, a assistência atua apenas enquanto o indivíduo não possuir meios de prover a própria manutenção ou de tê-la provida por sua família (arts. 20, caput, e 21, caput, da Lei 8.742/93); serviços públicos marcados pela universalidade e pela gratuidade, como a saúde, art. 196, e a educação, arts. 208 e 213, §1ํ.

Bonavides (2007, p. 200-201), alerta para o perigo a que se sujeita o Estado social da democracia:

O Estado, que, em si, por sua natureza mesma, já é uma organização de domínio, pode, sob o leme de governantes ambiciosos e de vocação autocrática, destituídos de escrúpulos, converter-se em aparelho de abusos e atentados à liberdade humana, o qual exploraria, no interesse de sua forma e de seu predomínio, aquela dependência básica do indivíduo, 


\title{
Personalidade Acadêmica Homenageada: \\ Florisbal de Souza Del'Olmo (Professor Convidado - UNICURITIBA)
}

transformado, então, em mero instrumento dos fins estatais. (...) $O$ demagogo ou plutocrata poderá ter o Estado social sob seu controle, de modo que aquilo que ele faz passar nos parlamentos como sendo a vontade social, seria em determinados casos, apenas a legislação dos grandes consórcios econômicos e financeiros, democraticamente legitimados.

Essa vontade social, assim forjada pelos grupos de pressão, aumenta e diminui, na estrutura do moderno Estado social, à medida que a participação efetiva do povo, por via de representantes autênticos, progride ou decai. Ocorre também a despolitização crescente do eleitor no Estado social da democracia moderna, como é o caso do Brasil, onde o comparecimento às urnas ocorre de maneira mecânica. (BONAVIDES, 2007, p. 202)

Boaventura Souza Santos, na obra já citada, relata que o modelo de Estado social vem sendo "atacado a partir dos anos 1970 até a seu cume nos anos 1990 por um modelo alternativo, designado por neoliberalismo ${ }^{5}$, que assenta na substituição da primazia do Estado pela do mercado na regulação social." $E$ continua:

\begin{abstract}
É um ataque ideológico, ainda que disfarçado de uma nova racionalidade econômica. São muitas as razões para a crescente agressividade deste ataque, mas todas elas têm em comum o serem fatores que favorecem a transformação da ideologia em pretensa racionalidade. Eis algumas delas: 0 modelo neoliberal está centrado na predominância do capital financeiro (sobre o capital produtivo) e para ele só há curto prazo; ou o médio prazo é, quando muito, alguns minutos mais; com o tempo, os trabalhadores e seus aliados transformaram a opção socialista, de incerta e distante, em opção esquecida, e passaram a aceitar, como vitórias, perdas menores, que só são menores porque vão sendo seguidas por outras maiores; o trabalho assalariado alterou-se profundamente e transformou-se num recurso global, sem que, entretanto, se tenha criado um mercado globalmente regulado de trabalho; o "compromisso histórico" gerido pelo Estado nacional transformase num anacronismo quando o próprio Estado passa a ser gerido pelo capital global.
\end{abstract}

\footnotetext{
${ }^{5} \mathrm{O}$ neoliberalismo nasceu após a II Guerra Mundial, nas regiões da Europa e dos Estados Unidos, onde imperavam mais fortemente o capitalismo, como uma reação teórica e política contra o Estado de bem-estar social. Tem como base o texto de Friedrich Hayek O Caminho da servidão, de 1944, que ataca qualquer limitação dos mecanismos de mercado por parte do Estado, denunciadas como uma ameaça à liberdade econômica e política.
} 


\section{Personalidade Acadêmica Homenageada:}

Florisbal de Souza Del'Olmo (Professor Convidado - UNICURITIBA)

Os governos democráticos que se sucederam a partir de 1985 no Brasil, adotaram inúmeras políticas neoliberais, cujos desdobramentos mais evidentes foram as privatizações de inúmeras empresas estatais.

O governo do presidente Fernando Henrique Cardoso, 1994-2002, editou a Lei 8031/90, revogada pela Lei 9491/97, que estabeleciam o Programa Nacional de Desestatização, adotando o modelo neoliberal como direcionador do Estado.

Seu sucessor, Luís Inácio "Lula" da Silva, recuperou as ideias do Estado providência, investindo em políticas sociais que resultaram na diminuição dos índices de pobreza e no aumento do poder aquisitivo da população, além de incentivar a produção e exportação, aquecendo a economia, dentro do modelo capitalista. Tais políticas sociais se mantiveram no governo de sua sucessora, Dilma Rousseff. No entanto, os investimentos em políticas sociais ainda são pequenos e mal administrados no Brasil.

O governo de Michel Temer, sucessor de Dilma Rousseff, retomou políticas neoliberais, investindo novamente em desestatização; promulgando nova legislação trabalhista, que precariza as condições do trabalhador e enfraquece os sindicatos; e apresenta projeto de reforma da previdência social, considerado o centro da política de desmonte (ou reestruturação, como preferem os políticos de direita) do Estado do bem-estar brasileiro.

Bresser-Pereira discorre sobre a crise do Estado social em seu já citado artigo, nos seguintes termos:

O capitalismo do após-guerra foi, portanto, um capitalismo social e desenvolvimentista. Entretanto, em função da queda da taxa de lucros que ocorre nos anos 1970, no início dos anos 1980 começa a se configurar uma nova forma de capitalismo caracterizado pela abertura comercial e financeira a mais ampla possível e pelo predomínio econômico das grandes empresas multinacionais e dos capitalistas rentistas e financistas associados a elas.

Continua discorrendo sobre a crise, explicando o fenômeno da globalização:

A globalização veio acompanhada por uma ideologia liberal radical - o neoliberalismo - que passou a rejeitar a combinação dialética entre liberalismo econômico e nacionalismo econômico desenvolvimentista que 


\title{
Personalidade Acadêmica Homenageada:
}

Florisbal de Souza Del'Olmo (Professor Convidado - UNICURITIBA)

\begin{abstract}
caracterizara as formas anteriores de capitalismo: a mercantilista, a liberal e a dos anos dourados. A nova doutrina hegemônica declarou o fim da nação e do Estado-nação, passou a ver o mercado como um mecanismo quase milagroso de coordenação econômica, deu absoluta precedência à liberdade individual, entendida esta como a liberdade e o poder dos mais fortes, e subordinou os demais objetivos a esse conceito de liberdade.
\end{abstract}

E, no seu entender, Bresser-Pereira descreve quem passa a deter o poder econômico nesse novo modelo neoliberalista, ensinando que houve uma evidente divisão entre os fortes - capitalistas rentistas, financistas, dirigentes das empresas multinacionais, seus consultores, seus advogados, seus economistas e, naturalmente, seus políticos -, detentores do poder econômico, e os fracos - os dominados, os trabalhadores, os empresários industriais que não fazem parte das "cadeias de valor", os pequenos e médios agricultores, as classes médias burguesas e empregadas, os habitantes das cidades médias e pequenas.

Diz ainda o autor sobre a globalização financeirizada, que está "foi uma reação à nova concorrência representada pelas exportações de bens industriais por países com mão de obra barata - os Newly Industrializing Countries (NICs): Coreia do Sul, Taiwan, Singapura, Hong-Kong, Brasil e México".

Da exposição de Bresser-Pereira, evidencia-se que com o neoliberalismo, o controle econômico tende a sair das asas do Estado, para novamente se "autorregular", regulação esta, altamente influenciada pelos fortes capitalistas rentistas e financistas, sempre visando o lucro imediato, mesmo que para tal viole direitos fundamentais previstos constitucionalmente.

\section{CONCLUSÃO}

Os traços característicos do Estado liberal, liberdade individual, propriedade privada, garantias jurídicas e igualdade formal são submissos ao patrimônio coletivo, onde o Estado social intervém na ordem econômica e social. O Estado legislador é substituído pelo Estado gestor, ao Estado estático contrapõe-se o Estado das prestações sociais, intervencionista. 


\section{Personalidade Acadêmica Homenageada:}

Florisbal de Souza Del'Olmo (Professor Convidado - UNICURITIBA)

No Brasil, o Estado social tem seus primeiros indícios no Império, com a Constituição de 1824, mas se desenvolve a partir da Era Vargas, que adota na Constituição de 1934 e de 1937, princípios de proteção social e fomentadores da industrialização e do nacionalismo econômico.

Marcado por ditaduras, o Estado brasileiro teve dois momentos democráticos mais longos entre 1945 e 1964 e o atual. Apesar da Constituição de 1967, pós golpe militar de 1964, prever direitos sociais, não os efetivava de fato.

A democracia foi consagrada a partir da Constituição de 1988, que possui um amplo e denso programa social que visa em ultima instância a concretização da igualdade e da justiça social. Isso é confirmado pelo extenso rol de direitos sociais previstos na carta.

Contudo, a crise do Estado social na Europa e nos Estados Unidos, nas décadas de 1970, 1980 e 1990, influenciou os governos democráticos brasileiros, que a partir de 1985, com a ruptura do Estado autoritário, passou a adotar medidas chamadas neoliberais, como as desestatizações ocorridas no governo Fernando Henrique Cardoso (1994-2002).

Os moldes do Estado de bem-estar social foram retomados a partir do governo Lula, que implementou diversas políticas sociais que reduziram o índice de pobreza, e ainda incentivou a economia nos moldes do capitalismo, que se mantiveram no governo Dilma Rousseff.

No governo de Michel Temer, restabelecem-se políticas neoliberais, retomando as desestatizações; alterando a legislação trabalhista, com a consequente precarização das condições de trabalho e enfraquecimento dos sindicatos; além de apresentar projeto de reforma da previdência social, sob o fundamento de ser uma "reestruturação" do Estado, e não um desmonte do Estado do bem-estar social brasileiro.

A desestruturação do Estado do bem-estar viola direitos fundamentais (econômicos, sociais e culturais), que deveriam ser efetivamente garantidos aos cidadãos, para que pudessem sentir-se livres e em nível de igualdade social, para influir no cenário político democrático. Como esses direitos não raro demandam posturas positivas, deveria ser o Estado o seu principal concretizador. 
Personalidade Acadêmica Homenageada:

Florisbal de Souza Del'Olmo (Professor Convidado - UNICURITIBA)

Se o Estado social e democrático de direito não é a melhor maneira de estruturar o Estado, talvez seja no mínimo uma tentativa comprometida seriamente em preservar direitos sociais importantes (saúde, trabalho, educação e previdência social) e em manter canais nas instituições oficiais para permitir que os cidadãos transformem o mundo em um lugar mais justo, em detrimento do poder capitalista.

\section{REFERÊNCIAS}

BONAVIDES, Paulo; ANDRADE, Paes de. História constitucional do Brasil. 8 ed. Brasília: OAB editora, 2006.

. Do Estado liberal ao Estado social. 8 ed. São Paulo: Malheiros, 2007.

. Reflexões sobre nação, Estado social e soberania. Estudos Avançados v. 22, n. 62, IEA-USP, 2008, p. 195-206. Disponível em: <http://www.scielo.br/pdf/ea/v22n62/a13v2262.pdf >. Acesso: 27 fev. 2018.

BRASIL. Constituição Federal de 1988. Disponível em: < http://www.planalto.gov.br/ccivil_03/constituicao/constituicaocompilado.htm>. Acesso em 28 fev. 2018.

BRESSER-PEREIRA, Luiz Carlos. Reforma gerencial e legitimação do estado social. Revista de Administração Pública. FGV:2017, vol.51, n.1, p.147-156. Disponível em: $<$ http://www.scielo.br/scielo.php?script=sci_arttext\&pid=S003476122017000100147\&lng=en\&nrm=iso >. Acesso: 27 fev. 2018.

CANCIAN, Renato. Estado do bem-estar social: história e crise do Welfare State. Disponível em: <https://educacao.uol.com.br/disciplinas/sociologia/estado-do-bemestar-social-historia-e-crise-do-welfare-state.htm>. Acesso: 28 fev. 2018.

HUBERMAN, Leo. História da riqueza do homem. 21 ed. Rio de Janeiro: LTC, 1986.

REGONINI, Gloria. Estado do Bem-Estar. In: BOBBIO, Norberto et al. (Org.). Dicionário de política. Brasília: UNB, 1983.

ROCHA, José de Albuquerque. Estudos sobre o Poder Judiciário. São Paulo: Malheiros, 1995.

SANTOS, Boaventura Sousa. O Estado social, Estado providência e de bem-estar. In Diário de notícias. Disponível em: <https://www.dn.pt/opiniao/opiniao- 
Personalidade Acadêmica Homenageada:

Florisbal de Souza Del'Olmo (Professor Convidado - UNICURITIBA)

dn/convidados/interior/o-estado-social-estado-providencia-e-de-bem-estar2968300.html>. Acesso: 27 fev. 2018.

SILVA, José Afonso. O Estado Democrático de Direito. Revista de Direito Administrativo, v. 173, Rio de Janeiro, 1988, p. 15-24. Disponível em: <http://bibliotecadigital.fgv.br/ojs/index.php/rda/article/\%20viewFile/45920/44126>. Acesso 27 fev. 2018. 